\title{
30 YEARS OF THE MINERALOCORTICOID RECEPTOR The scientific impact of cloning the mineralocorticoid receptor: 30 years on
}

\author{
John W Funder ${ }^{1,2}$ and Maria-Christina Zennaro $3,4,5$ \\ ${ }^{1}$ Hudson Institute, Clayton, Australia \\ 2Monash University, Clayton, Australia \\ ${ }^{3}$ Inserm, UMRS_970, Paris Cardiovascular Research Center, Paris, France \\ 4Université Paris Descartes, Sorbonne Paris Cité, Paris, France \\ ${ }^{5}$ Assistance Publique-Hôpitaux de Paris, Hôpital Européen Georges Pompidou, Service de Génétique, \\ Paris, France
}

\author{
Correspondence \\ should be addressed \\ to J Funder \\ Email \\ john.funder@hudson.org.au
}

The 41st annual meeting of the International Aldosterone Conference (IAC) was held in Boston, on 29 and 30 April 2016. There was a time when the IAC was heavily supported by industry, by invitation only, fares covered for speakers and accommodation for all attendees. Now the corporate cupboard is bare, except perhaps for clinical trials of compounds in development; those freely registering for the IAC now are half the number there were in the times of plenty, pay a non-trivial registration fee and cover their own expenses.

In 2016, the Journal of Endocrinology made a modest financial contribution to the IAC, support which was very welcome. In addition to their support, members of the editorial office suggested to one of us (J W Funder) that as 2017 marks the 30th anniversary of the cloning of the human mineralocorticoid receptor (hereafter MR), a commemorative special issue of the journal might be in order. Their suggestion was readily accepted, provided that Maria-Christina Zennaro was prepared to act as a co-editor. This was agreed, timelines and logistics set in place (more or less), invitations issued and gradually only a minority before the 31 December deadline - the contributions came in.

All were subject to the normal journal processes of refereeing, and in addition subjected to review by both special-issue editors: the native English speaker of the duo is regarded by his friends as a stickler for correct language, and by others as a hopeless pedant. We issued a dozen invitations, on the basis that in the unlikely event that all were accepted it would constitute a bumper issue, across the spectrum of MR studies. The two co-editors were held in reserve, in terms of contributing chapters: in the event there were eight acceptances to the invitations, and the co-editors then both became contributors.

Each of the contributions comes from experts in their particular fields. With ten reviews many, but not all, of the areas in which MR are involved are covered in detail. For example, nobody has canvassed potential roles for MR in what might be called second-order tissues of interest - the lung, adipose tissue, skin, gonads, breast, eye, ear, etc. Where there is a focus, it is on the heart, vasculature, kidney and central nervous system, understandably in line with the 'big' clinical issues of hypertension, heart failure, renal disease, stress and cognitive decline. Other contributions are more mechanistic - MR evolution, MR mutations, MR coregulators, MR specificity and MR deletion. To wrap it all up, in a sense, is an up-tothe-minute consideration of MR antagonists. We do not pretend to present an encyclopaedia, but what we have got is a series of up-to-date reviews, covering the past 30 years, by authors acknowledged to be experts in their chosen field(s).

There is no better place to start than with evolution. We now know that the MR evolved millions of years ago, in cartilaginous and bony fish, before the first appearance of aldosterone in lungfish, as their name implies a

This paper is part of a thematic review section on 30 Years of the Mineralocorticoid Receptor. The guest editors for this section were

John Funder and Maria,Christina ZennarQioscientifica.com at 04/26/2023 11:07:09AM 
transitional creature with both gills and lungs. This needs to be remembered before the otherwise too-easy assignation is made of aldosterone as the 'cognate' ligand for MR. Michael Baker is the undisputed leader in this area, combining his own studies with those of others to provide powerful insights into the probabilities underpinning MR evolution (Baker \& Katsu 2017). Sequence is one thing, structure something else and function something else again. His command of the possibilities of structure and the functional consequences thereof are remarkable: he has a mind like a flesh-and-blood 3-D printer.

One of the basic conundrums posed by - or perhaps better for - MR is that they have equivalent, high affinity for cortisol, corticosterone, deoxycorticosterone, aldosterone and progesterone. Normally, the physiological glucocorticosteroids circulate at levels $\sim 1000$-fold higher than aldosterone; the question then is what allows aldosterone selectively to activate epithelial MR, to retain $\mathrm{Na}^{+}$and excrete $\mathrm{K}^{+}$, which we know it does. Two years after the cloning of the MR we thought we had the answer that cortisol could not occupy epithelial MR because it was metabolized in these tissues to receptor-inactive cortisone. As has been previously noted, all really great lies are half true (Funder 1979); in this instance, both laboratories jumped to what appeared to be the obvious conclusion rather than consciously fabricating fake news. In a brief historical review of pre-receptor specificity-conferring mechanisms in epithelia, John Funder documents the context-dependent bivalent (agonist, antagonist) role of cortisol in MR, an unanticipated inverse agonist action of spironolactone on MR, and points to the sorts of studies that the next generation might consider to refine these concepts and set them in their appropriate physiological space (Funder 2017).

Pre-receptor specificity is one thing: intracellular regulation of liganded MR by coregulators (coactivators, corepressors) adds another level of tissue-specific action, depending upon which coregulators are expressed in each tissue, and the balance between activators and repressors. Although over 400 coregulatory proteins have been reported across the 48 (human)/49 (mouse) nuclear receptor superfamily - a bewildering array, particularly as many show additional signalling and other functional activities - relatively few have been described for MR. Whether this is actually the case, or reflects a field relatively untilled until recently, remains moot; MR have long been the Cinderella among the MR/GR/PR/AR/ER, probably reflecting the synthesis of spironolactone 60 years ago, and the much later efforts to synthesize and define antagonists/tissue-selective antagonists for the other steroid receptors. What Peter Fuller and his colleagues have done is to present what is currently known about ligandand tissue-specific selectivity conferred by MR-coregulator interactions, and to sketch what will be needed to guide other than hit-and-miss efforts, or good fortune, in the design of tissue-specific molecules inhibiting MR action via interacting with coregulators (Fuller et al. 2017).

Remaining in the realm of physiology, Shigeru Shibata presents a dazzling update on MR in the renal distal nephron (Shibata 2017). We were all taught in Physiology 101 that aldosterone acts to retain sodium and excrete potassium by activating MR in the principal cells of the connecting tubule and the collecting duct, where MR are abundant and $11 \beta \mathrm{HSD} 2$ is highly expressed. No longer: Shigeru is a young nephrologist with impeccable credentials: initial training with Toshiro Fujita at the University of Tokyo, and then to Yale with Rick Lifton. He canvasses the ways in which MRs are involved in $\mathrm{Na}^{+}$and $\mathrm{K}^{+}$homeostasis: the most novel of the findings is that in the intercalated cells MRs are phosphorylated on serine 843 in the ligand binding domain, and thus transcriptionally inactive. The circumstances whereby these MRs are dephosphorylated, how they contribute to the necessarily disparate regulation of $\mathrm{Na}^{+}$retention/ $\mathrm{K}^{+}$excretion and the physiologic ligand in their eventual activation, represent one of the most wonderful - in the sense of wonder-inducing - discoveries in the canon of MR physiology.

From the kidney to the brain. Bruce McEwen, the grandfather of corticosteroids and the central nervous system (hereafter CNS), described two distinct types of receptors in the CNS - high affinity sites binding $3 \mathrm{H}$-dexamethasone in the pituitary and 'corticosteronepreferring' sites in the hippocampus. On a range of indices, the latter were shown to be identical to renal MR by the late Zig Krozowski, and on these twin pillars, the field has blossomed, almost exponentially. The team of Marianne Joëls and Ron de Kloet has taken on the challenge of non-epithelial MR in the brain, that is the last frontier (as perhaps echoed in their title, 'The brain mineralocorticoid receptor: a saga in three episodes'; Joëls $\&$ de Kloet 2017). These MRs may be non-epithelial, but some (e.g. in the nucleus tractus solitarius) are 11ßHSD2 protected and are aldosterone responsive. The remainder are high-affinity cortisol receptors, with some functions proposed, a few established, and many yet to be identified (which, incidentally, is also the case for cortisol-occupied MR in other non-protected tissues). 
From the brain to the blood vessels. Although blood vessels are clearly not classical epithelia, both endothelium and smooth muscle cells express the specificity-conferring enzyme $11 \beta \mathrm{HSD} 2$. This is an area where acknowledgment of its role in the genesis of MR-dependent hypertension has been laggardly: most text books/journal articles hew steadfastly to epithelial sodium retention and volume expansion as the drivers of elevated blood pressure in primary aldosteronism, for example. Among the authors of this collection, there are a structural biologists, endocrinologists, nephrologists, neuroscientists, medicinal chemists and cell biologists and one cardiologist. Iris Jaffe and her colleague Jennifer Dupont over the past 15 years have harnessed the power of molecular biology, to make defining contributions to the roles of MR in the vasculature, in regulating blood pressure and in disease states - hypertension, obesity, stroke, myocardial infarction, atherosclerosis - and across differences in age and sex (Dupont \& Jaffe 2017).

The three previous contributions have each used the techniques of molecular biology to pose and then answer questions. Those techniques depend not only on receptor cloning but also on the generation - systemic or restricted - of receptor null (hereafter $\mathrm{KO}$ ) animals, almost always mice. Tim Cole was a post doc in Gunther Schutz's laboratory in Heidelberg, and a major contributor to the genesis of both the GRKO and MRKO mouse. Initially, $\mathrm{KO}$ was systemic; subsequently, the development of 'MR floxed' mice has allowed tissue-selective MRKO by crossing tissue-specific CRE-recombinase mice with MR-floxed mice. Tim and his colleague Morag Young take the reader through the development and refinement of MRKO, the phenotypes produced and the insights afforded, and very importantly note the 'second-order' MR-expressing sites yet to be targeted (Cole \& Young 2017).

There is a very old, rather noir joke - useful in medicolegal circles - about more of us using lawyers rather than rats as laboratory animals. First, rats are getting expensive, and there are lawyers everywhere. Second, rats bleed. Third, you can get quite fond of rats. Finally, there are some things that you just cannot get a rat to do. A jest, maybe, but what it underlines is that despite the commonalities, studies in mice pose rather than necessarily answer the same issues in humans. We cannot freely and blindly generalize from mouse to man - or even from mouse to rat: one has a gall bladder, for instance, and the other does not. This is where the contribution from Paris, by Maria-Christina Zennaro and Fabio FernandesRosa, comes in (Zennaro \& Fernandes-Rosa 2017).
Mineralocorticoid receptor mutations - the classical, Victor McKusick experiments of nature - can be construed with confidence as illuminating pathophysiology, and in most cases, adding to our appreciation of the underlying physiology that has been disrupted. Such mutations may be gain of function or loss of function, both relatively rare; more frequently reported are single-nucleotide MR polymorphisms associated with blood pressure, salt sensitivity, stress and depression, in many ways still workin-progress.

The two final contributions address other, important facets of MR action. Inevitably, these make use of the cellular/molecular biology techniques flowing from the cloning of the MR; both have histories that go back well before 1987. The first of these relates to the acute, nongenomic effects of aldosterone as opposed to those via DNA-directed, RNA-mediated protein syntheses. These were first reported by Fran Ganong and Pat Mulrow half a century ago, in in vivo studies on $\mathrm{Na}^{+}$retention following aldosterone infusion into the kidney of anaesthetized dogs: a clinical example, which has puzzlingly attracted limited attention, is the acute aldosterone secretion and vascular response to orthostasis. In the 1990s, there were reports of acute aldosterone effects via non-MR-mediated mechanisms: Claudia Grossman was among the first to show that most - but perhaps not absolutely all - rapid effects of aldosterone are indeed via MR. With her colleagues Stefanie Ruhs and Ralf Hübschriann, she has provided a comprehensive, up to date and very balanced discussion of MR - and its interaction with membrane receptors/proteins - in the acute effects of aldosterone (Ruhs et al. 2017).

The last paper addresses MR antagonists. Spironolactone is now in increasingly widespread clinical use, in primary aldosteronism, progressive cardiac failure and as adjuvant therapy in resistant hypertension. The drug was patented over 50 years ago, and remains widely used despite side effects reflecting its non-selectivity: in addition to its MR antagonist activity, it is an androgen receptor antagonist and a progestational agonist. This non-selectivity is associated with dose-dependent gynaecomastia in men and less frequently mastodynia in women; in addition, its progestational action commonly interferes with the menstrual cycle in younger women. A second-generation MR antagonist, eplerenone, is less potent but much more selective: in addition, it is very expensive and only varyingly recompensable in practice. A third-generation agent would be non-steroidal, as potent as spironolactone, as selective as eplerenone, cheap to
Published by Bioscientifica Ltd 
manufacture (unlike eplerenone) and with a long patent life. A fourth-generation agent would be all of the above, and tubule sparing.

There are a number of companies still active in this space, and a number who have dropped out. Arguably in the lead is Bayer AG, in Germany, which is currently in phase 3 trials of finerenone. Peter Kolkhof and Lars Bärfacker have combined to survey the history of 60 years of MR antagonist development, and they then focus on why eplerenone was chosen more than 20 years ago over its congeners, and similarly finerenone over its. Again the presentation is comprehensive, up to date and very well balanced, and should become the state-of-the-art reference against which further developments can be considered (Kolkhof \& Bärfacker 2017).

Finally, it might be asked why Ron Evans or Jeff Arriza, the first author of the cloning paper, are not contributors to this volume. The answer is that neither had a continuing interest in the MR beyond their seminal contribution (Arriza et al. 1987): a search of PubMed found only two (co-authored) subsequent MR-involving publications (Arriza et al. 1988, Rupprecht et al. 1993). Ron Evans' unwillingness thus reflects his modesty, and his magisterial commitment to other areas of endocrinology and metabolism. Together they provided the means to accelerate MR research, and we are their privileged beneficiaries: for what they achieved thirty years ago, we all owe them an enormous debt of thanks.

\section{Declaration of interest}

The authors declare that there is no conflict of interest that could be perceived as prejudicing the impartiality of this editorial.

\section{Funding}

J W F was supported by Victorian Government Infrastructure Support Program.

\section{References}

Arriza J, Weinberger C, Cerelli G, Glaser T, Handelin B, Housman D \& Evans R 1987 Cloning of human mineralocorticoid receptor complementary DNA: structural and functional kinship with the glucocorticoid receptor. Science 237 268-275. (doi:10.1126/ science.3037703)

Arriza JL, Simerly RB, Swanson LW \& Evans RM 1988 The neuronal mineralocorticoid receptor as a mediator of glucocorticoid response. Neuron 1 887-900. (doi:10.1016/0896-6273(88)90136-5)

Baker ME \& Katsu Y 201730 Years of the mineralocorticoid receptor: evolution of the mineralocorticoid receptor: sequence, structure and function. Journal of Endocrinology 234 T1-T16. (doi:10.1530/JOE-160661)

Cole TJ \& Young MJ 201730 Years of the mineralocorticoid receptor: mineralocorticoid receptor null mice: informing cell type-specific roles. Journal of Endocrinology 234 T83-T92. (doi:10.1530/JOE-17-0155)

DuPont JJ \& Jaffe IZ 201730 Years of the mineralocorticoid receptor: the role of the mineralocorticoid receptor in the vasculature. Journal of Endocrinology 234 T67-T82. (doi:10.1530/JOE-17-0009)

Fuller PJ, Yang J \& Young MJ 201730 Years of the mineralocorticoid receptor: coregulators as mediators of mineralocorticoid receptor signalling diversity. Journal of Endocrinology 234 T23-T34. (doi:10.1530/JOE-17-0060)

Funder JW 1979 All really great lies are half true. Science 2061139. (doi:10.1126/science.206.4423.1139)

Funder J 201730 Years of the mineralocorticoid receptor: mineralocorticoid receptor activation and specificity-conferring mechanisms: a short history. Journal of Endocrinology 234 T17-T21. (doi:10.1530/JOE-17-0119)

Joëls M \& de Kloet ER 201730 Years of the mineralocorticoid receptor: the brain mineralocorticoid receptor: a saga in three episodes. Journal of Endocrinology 234 T49-T66. (doi:10.1530/JOE-16-0660)

Kolkhof P \& Bärfacker L 201730 Years of the mineralocorticoid receptor: mineralocorticoid receptor antagonists: 60 years of research and development. Journal of Endocrinology 234 T125-T140. (doi:10.1530/ JOE-16-0600)

Ruhs S, Nolze A, Hübschmann R \& Grossmann C 201730 Years of the mineralocorticoid receptor: nongenomic effects via the mineralocorticoid receptor. Journal of Endocrinology 234 T107-T124. (doi:10.1530/JOE-16-0659)

Rupprecht R, Arriza JL, Spengler D, Reul JM, Evans RM, Holsboer F \& Damm k 1993 Transactivation and synergistic properties of the mineralocorticoid receptor: relationship to the glucocorticoid receptor. Molecular Endocrinology 7 597-603. (doi:10.1210/ mend.7.4.8388999)

Shibata S 201730 Years of the mineralocorticoid receptor: mineralocorticoid receptor and $\mathrm{NaCl}$ transport mechanisms in the renal distal nephron. Journal of Endocrinology 234 T35-T47. (doi:10.1530/JOE-16-0669)

Zennaro M-C \& Fernandes-Rosa F 201730 Years of the mineralocorticoid receptor: mineralocorticoid receptor mutations. Journal of Endocrinology 234 T93-T106. (doi:10.1530/JOE-17-0089)

Received in final form 11 May 2017

Accepted 11 May 2017 http://joe.endocrinology-journals.org

DOI: $10.1530 / J O E-17-0264$
() 2017 Society for Endocrinology Printed in Great Britain
Published by Bioscientifica Ltd. 